\title{
Effect of optic nerve lesions and intraocular colchicine on cell proliferation in the germinal zone of the optic tectum and in the torus longitudinalis in the goldfish
}

\author{
Roger E. Davis \\ Mental Health Research Institute, University of Michigan, Ann Arbor, MI 48109-1687 (U.S.A.)
}

(Accepted 8 August 1989)

Key words: Optic tectum; Torus longitudinalis; Neurotrophic stimulation; Brain cell proliferation; Goldfish; Optic nerve regeneration; Colchicine; Enucleation

\begin{abstract}
Postembryonic development of the optic tectum occurs in part through proliferation of cells in the germinal zone located at the caudal edges of each lobe. Autoradiography experiments by others have shown that $\left[{ }^{3} \mathrm{H}\right]$ thymidine labeling in the germinal zone is decreased following optic nerve crush or enucleation and restored above normal levels during optic nerve regeneration. The present autoradiography experiments examined the relationship between retinal innervation and the rate of mitotic activity in the tectum germinal zone and in the torus longitudinalis. The fish received optic nerve crush to temporarily deafferent the tectum, enucleation for permanent deafferentation, or an intraocular injection of $0.01-1.0 \mu \mathrm{g}$ of colchicine to reversibly inhibit axonal transport in the optic nerve. Thymidine labeling in the tectum germinal zone showed that nerve crush resulted in decreased mitotic activity in most fish within 6 days followed by recovery by 21 days; enucleation decreased mitotic activity more uniformly and for more than 42 days with recovery by 84 days postaxotomy; colchicine produced a dose-dependent inhibition of mitotic activity which was reversed by 42 days postinjection. Axonal transport was restored by 42 days postinjection. In the torus longitudinalis, nerve crush produced a brief increase in mitotic activity followed by a return to normal; enucleation and colchicine resulted in a lasting decrease in mitotic activity and atrophy indicating a loss of cells or neuropil. The data are consistent with the proposal that cell proliferation in the tectum germinal zone is stimulated by the accretion of fibers from developing retinal ganglion cells. Axonal transport of cellular materials in mature retinal fibers may also be involved. The results further suggest that the torus longitudinalis undergoes postembryonic development apace the optic tectum, and that its growth, like that of the tectum, is stimulated by the eye.
\end{abstract}

\section{INTRODUCTION}

The goldfish retina and optic tectum (OT) continue to develop late into life ${ }^{9,13,17}$. The postembryonic development occurs in part by the continued production of new neurons and glia in germinal zones that are located at the periphery of the retina and the caudal edges of the optic tectum $^{11,13.17}$. Developing retinal ganglion cells in the growing retina send ca. 50 new axons per day to the contralateral lobe of the $\mathrm{OT}^{4}$. Since new retinal afferents are presumably continuously integrated into the orderly pattern of retinotectal connections in the growing tectum, growth of the retina and of visual areas of the tectum may somehow be synchronized by the interconnecting retinal fibers.

An investigation of the effects of optic nerve lesions on the rate of cell proliferation in the tectum germinal zone (TGZ) has indicated that growth of the optic tectum may be controlled in part by the daily accretion of retinotectal fibers ${ }^{18}$. When one eye was removed, the ratio of the number of $\left[{ }^{3} \mathrm{H}\right]$ thymidine-labeled cells in the contrala- teral (Experimental) TGZ to the number in the ipsilateral (Control) TGZ was decreased below unity for the duration of the 30 day experiment. When the tectum was only temporarily deafferented by crushing the optic nerve, the ratio Experimental/Control decreased for ca. a week then increased above unity for the remainder of the 30 day experiment. Those authors related to the recovery and subsequent enhancement of mitotic activity in TGZ to regeneration of the retinotectal projection. Regenerating axons reach the contralateral tectum a week following nerve crush $\left(30^{\circ} \mathrm{C}^{21}\right)$ and they produce excess branches which persist for many weeks ${ }^{14}$. The surplus of retinal fibers and the coincident supranormal mitotic activity in the TGZ support the thesis that the arrival of retinal fibers stimulates TGZ cells to divide.

Although developmental theory has held that afferent fibers do not influence the proliferation of neurons in the vertebrate central nervous system ${ }^{8}$, the extended postembryonic development of the fish brain may present exceptions. The stimulation of growth and development of central visual system neurons by the eye is well

Correspondence: R.E. Davis, University of Michigan, Neuroscience Laboratory, 1103 E. Huron St., Ann Arbor, MI 48109-1687, U.S.A. 
established. But whether retinal afferents normally exert a trophic stimulating effect on the production of visual system neurons has been controversial. The finding that the eye regulates neurogenesis in the TGZ or the young adult goldfish is thus significant and needs further investigation.

How the eye might influence the rate of mitotic activity among TGZ cells is unclear. The TGZ cells could be innervated by retinal fibers, many of which pass nearby in the margin of tectum, or by fibers from cells in the tectum or torus longitudinalis, but ultrastructural studies report no evidence of such connections ${ }^{17}$. The present experiments were carried out to further investigate the effects of optic nerve crush and enucleation on mitotic activity in the TGZ and also to examine whether the activity is reversibly inhibited by an i.o. injection of colchicine that reversibly inhibits axonal transport in the retinotectal projection.

The putative trophic effect on TGZ might be mediated by molecules that are axonally transported from the retina in mature retinal afferents or the newly arriving fibers. Colchicine could also act by inhibiting growth of new retinal axons ${ }^{3}$ or by destroying retinal cells. To investigate whether retinal afferents were injured or destroyed, I measured mitotic activity in the OT as an index of gliogenesis related to axonal regeneration or degeneration ${ }^{23}$, and its size, as an index of fiber loss. For additional insight into the specificity of the trophic effect of retinal afferents on TGZ, I looked for experimental effects on the size and mitotic activity of the torus longitudinalis (TL). TL was chosen because of its functional ${ }^{15}$ and intimate physical relationship with $\mathrm{OT}^{6}$, ${ }^{24}$ and TGZ in particular.

\section{MATERIALS AND METHODS}

\section{Fish, surgery and experimental drugs}

Common goldfish, Carassius auratus L., $6-7.5 \mathrm{~cm}, 8-11 \mathrm{~g}$, obtained from Grassyforks Fisheries, Martinsville, IN, were kept at $30{ }^{\circ} \mathrm{C}$ in individual home tanks as previously described ${ }^{3}$. Since the goldfish retinotectal projection is almost entirely crossed ${ }^{20}$, with few fibers terminating in the ipsilateral tectum ${ }^{22}$, experimental treatments were administered to the right eye and the left eye served as the control. Fish were anesthetized by immersion in trimethane methyl sulfonate (Sigma) in tank water during surgery, intraocular injections and were euthanasia. The optic nerve was crushed 1-2 $\mathrm{mm}$ from the nerve head by pinching with a forceps. Enucleation consisted of removing the eyeball after cutting the optic nerve, ligament and eye muscles using a scissor. Colchicine, $\beta$-lumicolchicine (Sigma) in $5 \mu \mathrm{l}$ saline, or saline with no drug, were injected intraocularly (i.o.), into the posterior chamber of the right eye with the aid of a $10 \mu$ l Hamilton syringe.

\section{$l^{3}$ H]Thymidine labeling of brain cells and autoradiography}

Fish received an intracranial (i.c.) injection of $40-70 \mu \mathrm{Ci}$ of methyl $\left[{ }^{3} \mathrm{H}\right]$ thymidine, specific activity $89 \mathrm{Ci} / \mathrm{mmol}$, in $10 \mu l$ of water 22-24 $\mathrm{h}$ prior to euthanasia and preparation of the brain for histology. The brain was fixed in alcohol-formalin-acetic acid, embedded in Paraplast (Monoject) to obtain 15- $\mu$ m-thick transverse sections of the midbrain. Cells with ${ }^{3} \mathrm{H}$-labeled nuclei were localized by autoradiography. The slides were dipped in Kodak NTB-2 emulsion, exposed for 2-3 weeks then lightly stained with Cresyl violet $^{21}$

\section{Counting labeled cells}

The number of labeled cells in the Experimental (left) and Control (right) TGZ, TL, and OT was measured in 16 randomly selected sections from the caudal midbrain (Fig. 1). The examined sections were spaced one or more sections apart, the most caudal being 10-20 sections from the caudal extreme of TL. Labeled cells were counted using bright-field microscopy at $\times 200-320$ magnification, and. only relatively heavily labeled cells were counted. Labeled blood vascular cells were not counted. For this study, the dorsal boundary of $\mathrm{TL}$ was deemed to adjoin the intertectal commissure (Figs. 1 and 2); labeled cells that occurred ventral to the commissure including in the ependyma were counted as TL cells. In the case of the OT, the cell counts were made in the superficial white and gray zone and deeper layers including the granular layer of the periventricular gray zone (Figs. 1 and $2 \mathrm{~A}$ ). The more deeply lying fiber layer and epithelium of the paraventricular gray zone ${ }^{10,16}$ were excluded, as were the extreme dorsal medial and ventral lateral margins of the tectum containing the TGZ. TGZ cell counts were restricted to the dorsal medial portion of TGZ (Figs. 1 and 2A,B). The size of OT and TL were measured by measuring the area of their profiles in a section near the beginning and one near the end of the series that was used for cell counts.

The results were expressed as the ratio Experimental/Control (E/C) to minimize variance owed to uncontrolled differences in labeling between individuals ${ }^{18}$. Thus, mitotic activity was calculated

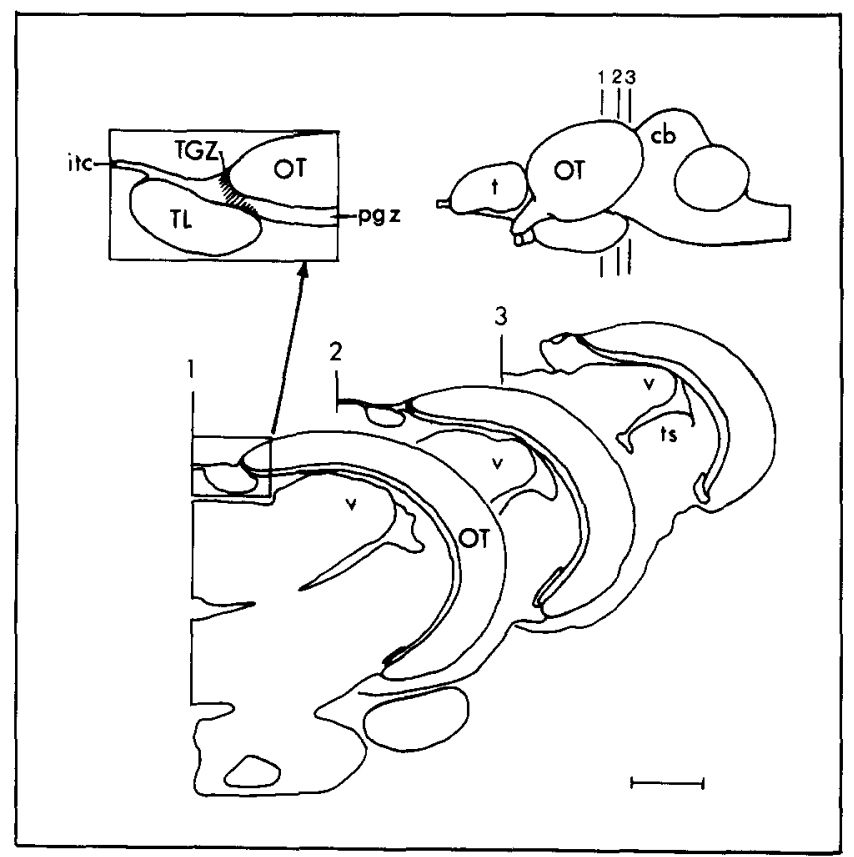

Fig. 1. Drawings of the left half of transverse sections of the cauda midbrain. The side view of the brain at the top of the Figure shows the locations of the sections. Counts of $\left[{ }^{3} \mathrm{H}\right]$ thymidine labeled cells in TGZ, TL and OT, and measurements of the size of TL and OT were made in the zone between sections 1 and 2 . Section 3 illustrates the approximate location of the end of TL. The inset shows the locations of TGZ, in the dorsal medial edge of OT, of TL and the intertectal commissure. cb, cerebellum; itc, intertectal commissure; OT, optic tectum; pgz, granular layer of the periventricular gray zone of OT; $t$, telencephalon; TGZ, tectum germinal zone; TL, torus semicircularis; ts, torus semicircularis; $v$, vavula of the cerebellum. Bar $=1 \mathrm{~mm}$. 


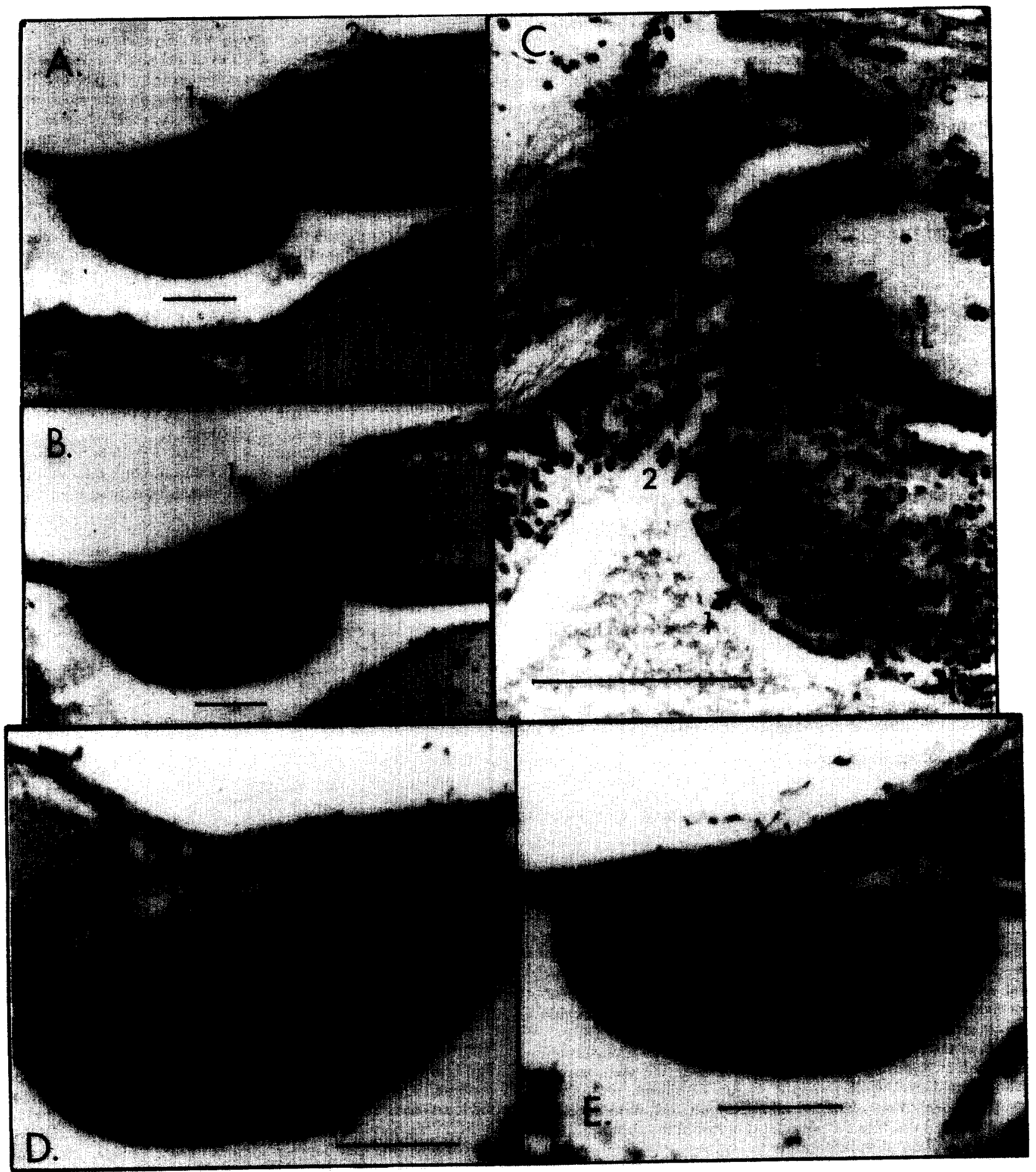

Fig. 2. A and B: representative actions from a radiolabeled brain of an intact control fish, which correspond approximately to sections 1 and F. 2. A and B: rels are also shown within TL and in its ependyma, and in v. C: a luxol-stained reference brain which shows, at arrow 1, the ependyma of TL. The section includes only the lateral

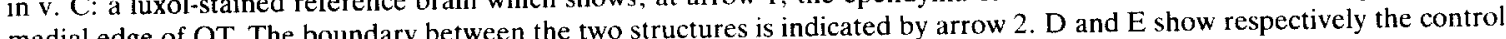
fifth of TL and the medial edge of OT. The boundary between the two structures. The TGZ in section D shows five heavily labeled cells. Bars and expe 
by dividing the average number of labeled cells in the Experimental TGZ, TL, or OT by the average in the corresponding Control structure. In TGZ, the absolute number of labeled cells per section were similar to those reported by Raymond et al. ${ }^{18}$. For example, a group of 7 intact fish that showed a mean $E / C$ of 1.02 (Table I) showed a mean of 2.70 labeled cells in TGZ on one side and 2.68 on the other. The means for TL in the same individuals were 4.71 and 4.90, and for OT, 7.08 and 8.52 . The E/C for size was similarly obtained from the averages of the two size measurements on each side of the brain.

\section{Measurement of axonal transport}

To measure fast axonal transport fish were administered $2 \mu \mathrm{Ci}$ of $\left[{ }^{3} \mathrm{H}\right]$ proline, specific activity $20-40 \mathrm{Ci} / \mathrm{mmol}$ (Amersham), in $2 \mu \mathrm{l}$ saline in the left eye. Following a $24 \mathrm{~h}$ period of incorporation the fish were euthanized and total protein and the amount of radioactivity in trichloroacetic acid (TCA)-precipitable protein was measured for each lobe of the optic tectum. In $\mathrm{dpm} / \mathrm{mg}$ of total protein in the left lobe was assumed to reflect uptake of systemically circulated $\left[{ }^{3} \mathrm{H}\right]$ proline. That amount was subtracted from the $\mathrm{dpm} / \mathrm{mg}$ total protein in the right lobe to determine the amount of labeled protein that was axonally transported from the left retina ${ }^{19}$.

\section{Experimental procedure}

Right optic nerve crush was administered to 17 fish. The fish were labeled for autoradiography and euthanized at 6 days postaxotomy (DPA; $n=6), 21$ DPA $(n=6)$ or 42 DPA $(n=5)$. Right eye enucleation was administered to another 24 fish that were similarly processed at 6 DPA $(n=5), 21 \mathrm{DPA}(n=6), 42 \mathrm{DPA}(n=7)$ or 84 DPA $(n=6)$. Additional fish that were kept intact were labeled and euthanized at 6 DPA $(n=7)$

To investigate the effects of colchicine on cell proliferation, fish administered an i.o. injection of colchicine in the right eye on experimental Day 1 were labeled and euthanized at 6,21 , or 42 days postinjection (DPI). The dose was $0.1(n=11), 0.5(n=10), 1(n$ $=11)$, or $2 \mu \mathrm{g}(n=14)$, and from 3 to 5 fish were labeled at each timepoint. Other fish received an i.o. injection of saline $(n=7)$ or $2 \mu \mathrm{g} \beta$-lumicolchicine and were kept for 6 days prior to processing for autoradiography. The derivative, lumicolchicine, which resembles colchicine in binding to various axoplasmic proteins but is a relatively weak inhibitor of microtubules or axonal transport ${ }^{1}$ was administered to control for possible non-specific effects of colchicine.

Colchicine inhibition of axonal transport was examined in fish that had received no other experimental treatment. Different individuals received saline with no drug $(n=11)$, or $0.01(n=17), 0.1(n=$ $20), 0.5(n=20)$ or $1.0 \mu \mathrm{g}(n=16)$ colchicine i.o. in the left eye on experimental Day 1. Axonal tranport was measured following 3 DPI for the saline fish and 3,14 or 42 DPI for the colchicine fish. From 5 to 10 colchicine fish were used at each timepoint. Lumicolchicine was omitted as previous behavioral and biochemical experiments had indicated that it does not inhibit axonal transport at doses of $1-2 \mu \mathrm{g}^{19}$.

\section{Data analysis}

The effects of crush or enucleation on the mean $\mathrm{E} / \mathrm{C}$ ratios for mitotic activity and size at the three survival times were evaluated using one-way ANOVAs and $t$-tests for independent means. Two-way ANOVAs and $t$-tests were used to evaluate the effects of the dose of colchicine and survival time on the $\mathrm{E} / \mathrm{C}$ ratios, and on the $\mathrm{dpm} / \mathrm{mg}$ of axonally transported retinal protein. BMDP statistical software was employed ${ }^{2}$.

\section{RESULTS}

\section{Optic nerve crush and enucleation}

The data for the crush and the enucleated fish were contrasted to data for intact fish as shown in Table I. The
ANOVAs revealed significant effects of crush on the E/C for mitotic activity in TGZ, TL and OT but not on size of TL or OT, whereas enucleation affected both mitotic activity and size. The data for the lesion and the intact fish were further contrasted in $t$-tests to evaluate the effects of survival time on mitotic activity and size.

$T G Z$. Following nerve crush, mitotic activity in the TGZ fluctuated greatly over time and between individuals. The mean $\mathrm{E} / \mathrm{C}$ was decreased at $6 \mathrm{DPA}$, suggesting that mitotic activity in the Experimental TGZ was inhibited, but it was not significantly different from the ratio for intact fish. The mean $\mathrm{E} / \mathrm{C}$ was significantly increased at 21 DPA, to more than twice unity, but at 42 DPA it was not significantly different from normal. The enucleates showed less variation. Mitotic activity in the Experimental TGZ showed significant inhibition at 6 and 42 DPA followed by recovery by 84 DPA.

$T L$. Labeled cells occurred throughout profile of TL but the majority were located in the ependyma (Fig. 2). Nerve crush produced increased mitotic activity in the experimental TL at 6 DPA but had no effect at later times, and size was unaffected. In contrast, enucleation resulted in decreased mitotic activity in the experimental TL from 6 to 42 DPA, and the size of TL decreased (Fig. $2 \mathrm{D}, \mathrm{E})$. There was no difference in the distribution of labeled cells between the control and experimental TL.

$O T$. As could be anticipated from studies of gliotic

\section{TABLE I}

Effect of optic nerve crush or enuclation on the number of labeled cells in TGZ, TL and OT, as an index of mitotic activity, and on the size of $T L$ and $O T$

Expressed as the ratio Experimental/Control.

\begin{tabular}{|c|c|c|c|c|c|}
\hline \multirow[t]{2}{*}{ Group } & \multirow{2}{*}{$\frac{T G Z}{\text { Mitotic }}$} & \multicolumn{2}{|l|}{$T L$} & \multicolumn{2}{|l|}{$O T$} \\
\hline & & $\begin{array}{l}\text { Micotic } \\
\text { activity }\end{array}$ & Size & $\begin{array}{l}\text { Mitotic } \\
\text { activity }\end{array}$ & Size \\
\hline Intact & 1.02 & 1.07 & 1.03 & 0.89 & 1.00 \\
\hline \multicolumn{6}{|l|}{ Nerve crush } \\
\hline 6DPA & 0.64 & $1.51^{*}$ & 0.96 & $9.41^{* *}$ & 0.99 \\
\hline $21 \mathrm{DPA}$ & $2.22^{* * * *}$ & 0.84 & 0.94 & $4.71^{* *}$ & 0.95 \\
\hline 42 DPA & 1.50 & 1.02 & 0.89 & 1.62 & 0.93 \\
\hline$F_{3,22}$ & $5.90^{* *}$ & $4.45^{*}$ & 2.95 & $16.32^{* * *}$ & 1.03 \\
\hline \multicolumn{6}{|l|}{ Enucleation } \\
\hline 6DPA & $0.51^{* *}$ & $0.52^{* * *}$ & $0.88^{*}$ & $1.29^{* *}$ & 1.00 \\
\hline 21 DPA & $0.55^{* *}$ & $0.38^{* * *}$ & $0.91^{*}$ & $0.47^{* *}$ & $0.83^{* * *}$ \\
\hline $42 \mathrm{DPA}$ & $0.61^{* *}$ & $0.56^{* * *}$ & $0.78^{* * *}$ & 0.90 & $0.78^{* * *}$ \\
\hline 84 DPA & 1.04 & $0.55^{* *}$ & $0.64 * * *$ & $0.50^{* *}$ & $0.68^{* * *}$ \\
\hline$F_{4,26}$ & $6.05^{* *}$ & $21.62^{* * *}$ & $15.64^{* * *}$ & $10.50^{* * *}$ & $18.21^{* * *}$ \\
\hline
\end{tabular}

$F$ values are for one-way ANOVAs contrasting the experimental and intact fish.

${ }^{*} P<0.05 ;{ }^{* *} P<0.01 ;{ }^{* *} P<0.001$. 
TABLE II

Summary of ANOVAs on the effects of the i.o. dose of colchicine and the period of survival

$\begin{array}{ll}\text { TGZ mitotic activity } & F_{3,34}=1.26 \\ \text { Dose } & F_{2,34}=17.05^{* * *} \\ \text { Day } & \\ \text { TL mitotic activity } & F_{3,34}=6.59^{* * *} \\ \text { Dose } & F_{2,34}=6.55^{* *} \\ \text { Day } & \\ \text { TL size } & F_{3,37}=4.13^{*} \\ \quad \text { Dose } & F_{2,37}=8.85^{* * *} \\ \text { Day } & \\ & \\ \text { OT mitotic activity } & F_{3,34}=1.10 \\ \text { Dose } & F_{2,34}=40.23^{* * *} \\ \text { Day } & \\ \text { OT size } & F_{3,37}=8.27^{* * *} \\ \text { Dose } & F_{2,37}=26.35 \\ \text { Day } & \end{array}$

reactions to nerve lesions, crush and enucleation resulted in transiently increased mitotic activity in the experimental OT. The reaction was greater and lasted longer following nerve crush. This agrees with the finding of Stevenson and Yoon ${ }^{23}$ that axonal regeneration following optic nerve crush stimulated gliogenesis in the optic tectum. In crush fish, the $\mathrm{E} / \mathrm{C}$ for mitotic activity was increased 10-fold at 6 DPA and 5-fold at 21 DPA and near normal by 42 DPA. In contrast, the enucleates showed only a slight increased OT mitotic activity at 6 DPA, and decreased or normal activity at later timepoints. The size of the experimental OT, which did not fluctuate significantly following crush, shrank increasingly over the 3 month period following enucleation.

\section{Intraocular colchicine}

The effects of colchicine varied with the dose and with the period of survival (Table II). There were significant effects of dose and day on mitotic activity and size in TL, and for size in OT, and of day but not dose on mitotic activity in TGZ and OT. Saline and lumicolchicine fish showed similar $\mathrm{E} / \mathrm{C}$ ratios near unity and their data were combined to form the normal control group. I expected that lumicolchicine would have no effect, based on our previous experiments in the regenerating goldfish optic nerve $^{3}$. The data for the controls and the colchicine fish (Table III) were contrasted in one-way ANOVAs and $t$-tests to further evaluate the effects of dose and day.

$T G Z$. Mitotic activity in the experimental TGZ was significantly inhibited for 6-21 DPI, and the duration of the inhibition increased with the dose. By 42 DPI mitotic activity was normal or slightly above normal.

$T L$. The experimental TL showed significant decreases
TABLE III

Effect of i.o. colchicine on the number of labeled cells in the experimental TGZ, TL, and $O T$, as an index of mitotic activity, and on the size of $T L$ and $O T$

Expressed as the ratio Experimental/Control

\begin{tabular}{|c|c|c|c|c|c|}
\hline \multirow[t]{2}{*}{ Group } & \multirow{2}{*}{$\begin{array}{c}T G Z \\
\text { Mitotic } \\
\text { activity }\end{array}$} & \multicolumn{2}{|l|}{$T L$} & \multicolumn{2}{|l|}{$O T$} \\
\hline & & $\begin{array}{l}\text { Mitotic } \\
\text { activity }\end{array}$ & Size & $\begin{array}{l}\text { Mitotic } \\
\text { activity }\end{array}$ & Size \\
\hline Control & 1.02 & 1.05 & 1.02 & 0.98 & 1.01 \\
\hline \multicolumn{6}{|l|}{$0.1 \mu \mathrm{g} \mathrm{Col}$} \\
\hline 6 DPI & $0.64^{*}$ & $0.72^{* *}$ & 0.93 & 2.00 & 1.00 \\
\hline 42 DPI & 1.04 & 1.04 & 0.99 & 1.10 & $0.92^{*}$ \\
\hline \multicolumn{6}{|l|}{$0.5 \mu \mathrm{g} \mathrm{Col}$} \\
\hline 6 DPI & $0.68^{*}$ & $0.71^{* *}$ & 0.98 & $4.43^{* * *}$ & 1.02 \\
\hline $21 \mathrm{DPI}$ & 0.77 & $0.63^{* *}$ & $0.85^{* *}$ & 0.50 & $0.80^{* *}$ \\
\hline 42 DPI & 1.11 & 0.93 & $0.84^{* *}$ & 1.07 & $0.89^{* *}$ \\
\hline \multicolumn{6}{|l|}{$1.0 \mu \mathrm{g} \mathrm{Col}$} \\
\hline $6 \mathrm{DPI}$ & $0.65^{*}$ & $0.74^{*}$ & 0.96 & $4.77^{* * *}$ & 0.91 \\
\hline 21 DPI & $0.62^{* *}$ & $0.52^{* * *}$ & $0.84^{* *}$ & 0.64 & $0.81^{* * *}$ \\
\hline 42 DPI & $1.38^{*}$ & $0.77^{*}$ & $0.78^{* * *}$ & 0.82 & $0.80^{* * *}$ \\
\hline \multicolumn{6}{|l|}{$2.0 \mu \mathrm{g} \mathrm{Col}$} \\
\hline $6 \mathrm{DPI}$ & $0.45^{* * *}$ & $0.62^{* * *}$ & 0.96 & $4.02^{* * *}$ & 0.98 \\
\hline 21 DPI & $0.59^{* *}$ & $0.35^{* * *}$ & $0.79^{* * *}$ & 0.58 & $0.80^{* * *}$ \\
\hline 42 DPI & 1.00 & $0.69^{* * *}$ & $0.72^{* * *}$ & 0.59 & $0.71^{* * *}$ \\
\hline$F_{12,43}$ & $4.89 * * *$ & $6.47^{* * *}$ & $5.85^{* * *}$ & $10.57^{* * *}$ & $10.62^{* * *}$ \\
\hline
\end{tabular}

in mitotic activity and size following the colchicine treatment, and both effects increased with the dose. Mitotic activity returned to normal by $42 \mathrm{DPI}$ in fish that received 0.1 or $0.5 \mu \mathrm{g}$ colchicine but remained inhibited in the fish that received 1 or $2 \mu \mathrm{g}$. Doses above $0.1 \mu \mathrm{g}$ resulted in atrophy of the experimental TL. The decrease in size appeared between 6 and 21 DPI and there was no sign of recovery by $42 \mathrm{DPI}$.

$O T$. Doses higher than $0.1 \mu \mathrm{g}$ resulted in a 4 -fold increase in the mitotic activity in the experimental OT at 6 DPA followed by a return to normal. The experimental OT was significantly decreased in size following doses of $0.1 \mu \mathrm{g}$ or higher, the effect increasing with the dose, and there was no significant recovery by $42 \mathrm{DPI}$.

Axonal transport. Axonal transport was reversibly inhibited by colchicine at doses above $0.01 \mu \mathrm{g}$ and the duration of the inhibition increased with the dose (Table IV). The two-way ANOVA on the colchicine data showed a significant dose effect: $F_{3,61}=15.38, P<0.001$, and day effect $F_{2,61}=22.76, P<0.001$; and a dose $\times$ day interaction: $F_{6.61}=3.69, P<0.01$. The $0.01 \mu \mathrm{g}$ dose produced equivalent deficits at 3 DPI. By 14 DPI the 0.1 $\mu \mathrm{g}$ fish showed some recovery of axonal transport, in contrast to the 0.5 and $1 \mu \mathrm{g}$ fish $(P<0.01)$, but by $42 \mathrm{DPI}$ 
TABLE IV

Inhibition of axonal transport of ${ }^{3} \mathrm{H}$-labeled retinal protein to the optic tectum following an i.o. injection of colchicine

Values are $\mathrm{dpm} / \mathrm{mg} \times 10^{3}$.

\begin{tabular}{llll}
\hline Dose & \multicolumn{2}{l}{ Survival time } & \\
\cline { 2 - 3 } & 3 Days & 14 Days & 42 Days \\
\hline Control & 6643 & & \\
& & & \\
$0.01 \mu \mathrm{g}$ & 5320 & 6445 & 6089 \\
$0.1 \mu \mathrm{g}$ & $1752^{* * *}$ & $4432^{* *}$ & 5387 \\
$0.5 \mu \mathrm{g}$ & $960^{* * *}$ & $1819^{* * *}$ & 6420 \\
$1.0 \mu \mathrm{g}$ & $1151^{* * *}$ & $1450^{* * *}$ & 4503 \\
\hline
\end{tabular}

${ }^{*} P<0.05 ;{ }^{* * *} P<0.01 ;{ }^{* * *} P<0.001$. One-way ANOVA $F_{12,71}=$ $10.11, P<0.001$

the colchicine fish were not significantly different from the controls.

\section{DISCUSSION}

\section{Germinal zone of the optic tectum}

The effects of the optic nerve lesions in these experiments and those of Raymond et al. ${ }^{18}$ are similar in showing that crushing the nerve near the eye or cutting the nerve and removing the eye results in decreased mitotic activity in the experimental as opposed to the control TGZ within a week. The data indicate that severing the retinal input inhibits the rate of cell proliferation in the contralateral TGZ for a period of up to several months. The data also suggest that regeneration of the retinal afferents tends to restore mitotic activity in the experimental TGZ but whether the reinnervation of the tectum is accompanied by a supranormal enhancement of cell proliferation in the TGZ is unclear.

At 21 WPA, the fish that received optic nerve crush showed unusually low numbers of labeled cells per section in the control TGZ. Mitotic activity in the experimental TGZ was increased over the activity at 6 DPA but it was not unusually high. Thus, looking at the absolute number of labeled cell suggested that the $\mathrm{E} / \mathrm{C}$ at 21 DPA was high mainly because the activity in the control TGZ was low. While the low value could be a chance occurrence reflecting a relatively large, uncontrolled, between-fish variation in uptake of $\left[{ }^{3} \mathrm{H}\right]$ thymidine, it is significant that the results of Raymond et al. ${ }^{18}$ show a similar abberancy.

Overall, in the two studies, the absolute numbers of labeled TGZ cells per section, and the mean $\mathrm{E} / \mathrm{C}$ ratios, for the crush fish and the enucleates were strikingly similar. Though the differences in experiment design preclude detailed comparisons, data from the two studies show that, on average, crush fish that were labeled 21-30
DPA exhibited the lowest number of labeled cells in the control TGZ. This correspondence between the two studies seems unlikely to be chance occurrence. It suggests that in the case of optic nerve crush the use of the $\mathrm{E} / \mathrm{C}$ ratio may be invalid. It is possible that axonal regeneration following nerve crush inhibits mitotic activity in the ipsilateral TGZ, though a mechanism is difficult to envisage. In my experiments, the experimental TGZ showed more labeled cells than the control TGZ at 21 and 42 DPA but the numbers were comparable to the numbers for the control TGZ in other groups and clearly not supranormal. This suggests that axonal regeneration results in recovery of mitotic activity in the experimental TGZ, rather than enhancement above normal. Experiments are clearly needed which control for possible bilateral effects of nerve crush on the TGZ.

The results for the enucleates suggest that inhibition of cell proliferation in the Experimental TGZ produced by permanent deafferentation was reversed within 84 DPA (Table I). The enucleates displayed no sign of unusually low mitotic activity in the control TGZ, as was seen in the crush fish, at any timepoint. The same was true for the colchicine fish. The groups of colchicine fish averaged from 2 to 5 labeled cells per section in the control TGZ. While the present experiments do not clearly show whether the treatments affected mitotic activity in the Control TGZ, I assume in this discussion that they did not and that the ratio $\mathrm{E} / \mathrm{C}$ reflects experimental effects on $\mathrm{E}$ and not $\mathrm{C}$.

Colchicine inhibited cell proliferation in the experimental TGZ and the duration of the inhibition varied with the dose and with the inhibition of fast axonal transport of newly synthesized retinal protein. The $0.1 \mu \mathrm{g}$ dose was previously shown to reversibly inhibit the regeneration of retinal afferents following optic nerve crush $^{3}$. Thus, in addition to inhibiting axonal transport of cellular materials in mature retinal fibers, the drug might have inhibited mitotic activity in the TGZ by inhibiting the arrival of new retinal afferents in the tectum. The latter action would be consistent with the theory that the rate of TGZ cell proliferation is maintained in part by the continuous accretion of retinal fibers ${ }^{18}$. However, the involvement of trophic substances axonally transported in mature retinal fibers cannot be ruled out.

Colchicine could also have acted by decreasing the number of existing retinotectal connections. The finding that the experimental OT atrophied following administration of $0.1 \mu \mathrm{g}$ or more suggests that the drug resulted in atrophy or elimination of retinal fibers in the tectum. However, we have shown that the retinotectal projection continues to mediate behavioral visual responses following an i.o. injection of 0.1 or $0.5 \mu \mathrm{g}^{3.19}$. In the present experiments, evidence of gliogenesis in the OT indicative 
of axonal degeneration, was obtained for $0.5 \mu \mathrm{g}$ or higher. Those doses produced similar increases in mitotic activity in the Experimental OT at 6 DPA, and similar degrees of inhibition of axonal transport (Table IV), as though $0.5 \mu \mathrm{g}$ was sufficient to produce maximum degeneration of retinal fibers in the tectum. Many fibers presumably survived, as axonal transport was restored to normal by 6 DPI. Additionally, the large increase in mitotic accivity in OT could indicate gliogenesis associated with axonal regeneration.

\section{Torus longitudinalis}

$\mathrm{TL}$ is an actinopterygian brain structure, not found in other vertebrates ${ }^{10}$. Anatomical studies in the carp, Cyrpinus carpio, and other teleosts suggest that the only target of TL neurons is the ipsilateral $\mathrm{OT}^{6,7,24}$. TL is innervated by the vavula, and possibly the $\mathrm{OT}^{6,7}$, but apparently receives no retinal afferents ${ }^{22}$. TL cells and neuropil are reported to resemble the granule cells and molecular layer of the vavula ${ }^{6}$. The output to the tectum consists of abundant, fine, unmyelinated fibers which terminate exclusively in the superficial marginal layer (SM) and synapse on dendrites from neurons in deeper layers of the tectum ${ }^{5.7}$ which also receive retinal afferents ${ }^{12}$. Thus, the experimental treatments might have produced their effects on TL by acting in some way on the marginal fibers.

The effects of enucleation and of i.o. colchicine show that the postembryonic growth of TL, like that of OT, may be regulated by the eye. The development of TL has apparently not been examined. The present results suggest that it may grow apace the optic tectum, and like the tectum ${ }^{17}$, it may grow mainly caudally. Whether the growth involves production of new neurons is unclear. I saw labeled cells along the entire length of $\mathrm{TL}$, most in or near the ependyma, and not only caudally.

The decrease in size and in mitotic activity in the Experimental TL following enucleation or i.o. colchicine suggests a loss of fibers and possible of cells as well. The TL fibers might atrophy or degenerate as a result of deleterious transynaptic effects in the tectum. Owing to the type of histological preparation, unlabeled cells and the boundaries of the layers of the tectum were poorly visualized in the experimental material. TL cells could not be accurately counted to see if the total number of cells decreased during long periods of inhibition. Also SM was not differentiable from the deeper layers of the tectum, so I could not determine if its thickness was

\section{REFERENCES}

1 Banks, P. and Till, R., A correlation between the effects of drugs on microtubule assembly in vitro and the inhibition of axonal transport in noradrenergic neurones, J. Physiol. (Lond.), 252 decreased. Cell density in the experimental TL of enucleates and colchicine fish appeared to be increased (Fig. 2D,E), suggesting that the main effect within TL was a decrease in the neuropil. TL fibers may have degenerated but there was no evidence of an associated proliferation of glial cells. Experiments by others ${ }^{5}$ in the OT of the squirrel fish, Holocentrus rufus, showed that enucleation produced extensive degeneration of the terminals of retinal afferents within 3 days, in fish kept at $25^{\circ} \mathrm{C}$, but no changes in the terminals of $\mathrm{TL}$ afferents in SM were detected. However, since the latency to the decrease in size of TL was more than 6 days in goldfish kept at $30^{\circ} \mathrm{C}$, it is possible that TL fibers degenerate secondarily, in response to the degeneration of retinal afferent terminals or related changes in the dendrites of their target cells.

The effects of nerve crush on TL were limited and difficult to interpret. The small but significant increase in mitotic activity in the experimental TL contrasted sharply with the pronounced inhibitory effects of enucleation and colchicine. The increase could reflect a proliferation of glial cells in TL, related to the conspicuous gliogenesis that occurs in OT following nerve crush, and would suggest that fiber connections between TL and OT were damaged.

\section{Mechanisms of retinal control of cell proliferation in $T G Z$ and $T L$}

The theory that the accretion of new fibers from the retina serves to maintain the rate of cell proliferation in the TGZ is weakened, but not disproved, by the evidence that mitotic activity in TGZ may not be enhanced above normal when regenerating axons reinnervate the OT. TGZ may normally be highly sensitive to whether new fibers are arriving in the tectum but relatively insensitive to the absolute number, in particular during regeneration of the entire retinotectal projection. The same may be true for cell proliferation in TL, though a different process is probably involved. It is interesting that mitotic activity recovered from colchicine inhibition by 42 DPA in TGZ but not in TL (Table III). Also, upon recovery some colchicine fish showed a slight enhancement of mitotic activity in the experimental TGZ, that could signify a response to increased branching of fibers following recovery from the drug. However, additional mechanisms should be explored. In any case, the present results suggest that the growth of both the OT and the TL is stimulated by the eye.

(1975) 283-294

2 Dixon, W.J., Brown, M.D., Engelman, L., Frane, J.W., Hill, M.A., Jennrich, R.I. and Toporek, J.D., BMDP Statistical Software, University of California Press, Berkeley, 725 pp.

3 Davis, R.E., Schlumpf, B.E. and Klinger, P.D., Comparative 
neurotoxicity of tubulin-binding drugs: inhibition of goldfish optic nerve regeneration, Toxicol. Appl. Pharmacol., 80 (1985) 308-315.

4 Easter, S.S., Rusoff, A.C. and Kish, P.E., The growth and organization of the optic nerve and tract in juvenile and adult goldfish, J. Neurosci., 1 (1981) 793-811.

5 Ito, H., Butler, A.B. and Ebbesson, S.O.E., An ultrastructural study of the normal synaptic organization of the optic tectum and the degenerating tectal afferents from retina, telencephalon, and contralateral tectum in a teleost, Holocentrus rufus, J. Comp. Neurol., 191 (1980) 639-659.

6 Ito, H., Fine structure of the carp torus longitudinalis, $J$. Morphol., 135 (1971) 153-164.

7 Itoh, H. and Kishida, R., Afferent and efferent fiber connections of the carp torus longitudinalis, J. Comp. Neurol., 181 (1978) 465-476.

8 Jacobson, M., Developmental Neurobiology, 2nd edn., Plenum, New York, 562 pp.

9 Johns, P.R., Growth of fish retinas, Am. Zool,, 21 (1981) 447-458.

10 Kappers, C.U., Huber, G.C. and Crosby, E.C., The Comparative Anatomy of the Nervous System of Vertebrates, Including Man, Vol. III, Hafner, New York, 1936, pp. 905-906.

11 Kirsche, W., Über postembryonale matrixzonen in Gehirn verschiedener Vertebrate under deren Beziehung zur Hirnbauplanlehre, Z. Mikorsk. Anat. Forsch., 77 (1967) 313-406.

12 Laufer, M. and Vanegas, H., The optic tectum of a perciform teleost. II. Fine structure, J. Comp. Neurol., 154 (1974) 61-96.

13 Meyer, R.L., Evidence from thymidine labeling for continued growth of retina and tectum in juvenile goldfish, Exp. Neurol. 59 (1978) 99-111.

14 Murray, M. and Edwards, M.A., A quantitative study of the reinnervation of the goldfish optic tectum following optic nerve crush, J. Comp. Neurol., 209 (1982) 373.

15 Northmore, D.P.M., Visual saccadic activity in the goldfish torus longitudinalis, J. Comp. Physiol. A., 155 (1984) 333-340.

16 Northcutt, R.G., Evolution of the optic tectum in ray-finned fishes. In R.E. Davis and R.G. Northcutt (Eds.), Fish Neurobiology, University of Michigan Press, Ann Arbor, 1983, pp. $1-42$.

17 Raymond, P.A. and Easter, S.S., Postembryonic growth of the optic tectum in goldfish. I. Location of germinal cells and numbers of neuron produced, J. Neurosci., 3 (1983) 1077-1091.

18 Raymond, P.A., Easter, S.S., Burnham, J.A. and Powers, M.K., Postembryonic growth of the optic tectum in goldfish. II. Modulation of cell proliferation by retinal fiber input, $J$. Neurosci., 3 (1983) 1092-1099.

19 Schlumpf, B.E. and Davis, R.E., Intraocular colchicine inhibits competition between resident and foreign optic axons for functional connections in the doubly innervated goldfish optic tectum, Brain Research, 386 (1986) 305-312.

20 Sharma, S.C., The retinal projections in the goldfish: an experimental study, Brain Research, 39 (1972) 213-223

21 Springer, A.D. and Agranoff, B.W., Effect of temperature on rate of optic nerve regeneration - autoradiographic and behavioral study, Brain Research, 128 (1977) 405-415.

22 Springer, A.D. and Gaffney, J.S., Retinal projections in the goldfish: a study using colbaltous lysine, J. Comp. Neurol., 203 (1981) 401-424.

23 Stevenson, J.A. and Yoon, M.G., Regeneration of optic nerve fibers enhances cell proliferation in goldfish optic tectum, Brain Research, 153 (1978) 345-351.

24 Vanegas, H., Morphological aspects of the teleostean optic tectum. In H. Vanegas (Ed.), Comparative Neurology of the Optic Tectum, Plenum, New York, 1984, pp. 93-120. 